\title{
Mutants of Lotus japonicus deficient in flavonoid biosynthesis
}

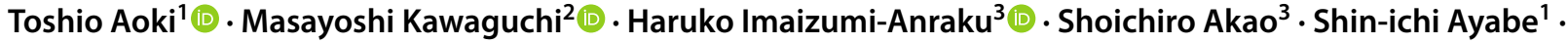 \\ Tomoyoshi Akashi ${ }^{1}$ (]
}

Received: 22 October 2020 / Accepted: 28 January 2021 / Published online: 11 February 2021

(c) The Author(s) 2021, corrected publication 2021

\begin{abstract}
Spatiotemporal features of anthocyanin accumulation in a model legume Lotus japonicus (Regel) K.Larsen were elucidated to develop criteria for the genetic analysis of flavonoid biosynthesis. Artificial mutants and wild accessions, with lower anthocyanin accumulation in the stem than the standard wild type (B-129 'Gifu'), were obtained by ethyl methanesulfonate (EMS) mutagenesis and from a collection of wild-grown variants, respectively. The loci responsible for the green stem of the mutants were named as VIRIDICAULIS (VIC). Genetic and chemical analysis identified two loci, namely, VICl and $V I C 2$, required for the production of both anthocyanins and proanthocyanidins (condensed tannins), and two loci, namely, VIC3 and VIC4, required for the steps specific to anthocyanin biosynthesis. A mutation in VIC5 significantly reduced the anthocyanin accumulation. These mutants will serve as a useful system for examining the effects of anthocyanins and proanthocyanidins on the interactions with herbivorous pests, pathogenic microorganisms and nitrogen-fixing symbiotic bacteria, Mesorhizobium loti.
\end{abstract}

Keywords Anthocyanin · Condensed tannin · Lotus japonicus (regel) K.Larsen · Mutant · Proanthocyanidin · VIRIDICAULIS

\section{Introduction}

Higher plants produce diverse flavonoid metabolites involved in a number of plant functions (Dixon and Steele 1999; Winkel-Shirley 2001), such as pigmentation, pollen fertility (van der Meer et al. 1992; Ylstra et al. 1994), auxin transport (Jacobs and Rubery 1988; Peer and Murphy 2007), hydrogen peroxide scavenging (Morimoto et al.

Toshio Aoki and Shoichiro Akao: deceased.

Masayoshi Kawaguchi

masayosi@nibb.ac.jp

Tomoyoshi Akashi

akashi.tomoyoshi@nihon-u.ac.jp

1 Department of Applied Biological Sciences, Nihon University, Fujisawa, Kanagawa 252-0880, Japan

2 Division of Symbiotic Systems, National Institute for Basic Biology, Okazaki, Aichi 444-8585, Japan

3 Institute of Agrobiological Sciences, National Agriculture and Food Research Organization, Tsukuba, Ibaraki 305-8634, Japan
1998; Yamasaki et al. 1997) and protection against harmful ultraviolet (UV) radiation (Chappell and Hahlbrock 1984; Li et al. 1993; Stapleton and Walbot 1994). Furthermore, flavonoids in leguminous plants play important roles (Aoki et al. 2000) in nodule formation as signal molecules (Franssen et al. 1992; Long 1996) or in defence responses as antimicrobial phytoalexins (Dixon and Paiva 1995). Flavonoids have also been implicated in root and nodule organogenesis (Charrier et al. 1998; Hassan and Mathesius 2012; Mathesius 2001; Mathesius et al. 1998; Spaink 1998; Subramanian et al. 2006; Wasson et al. 2006; Zhang et al. 2009) and architectural phenotypes (Buer and Djordjevic 2009).

Anthocyanins (blue-red pigments) are one of the principal classes of flavonoids. Pigments in reproductive organs serve as attractants for pollinators and seed dispersers. The biosynthesis of anthocyanins has been extensively studied, and the biosynthetic enzymes and genes involved have been characterized (Hrazdina 1982; Mulder-Krieger and Verpoorte 1994). Anthocyanin biosynthesis in Arabidopsis thaliana, maize kernels, morning glory and petunia and snapdragon flowers represents a good system for genetic studies, and several structural and regulatory genes in this pathway 
have been identified using these plant species (Forkmann 1994; Holton and Cornish 1995; Park et al. 2018; Sharma et al. 2011; Winkel-Shirley et al. 1995).

Proanthocyanidins, also known as condensed tannins, represent another class of flavonoid metabolites (Haslam 1998). These are flavonoid oligomers biosynthesized by a branch of the flavonoid pathway (Fig. 1) and have been shown to affect the resistance against herbivorous insects (Chan et al. 1978) and the interaction with nitrogen-fixing rhizobia (Jones et al. 1987; Punkhurst and Jones 1979). Bird's-foot trefoil (Lotus corniculatus L.), a leguminous forage crop, is characterized by the accumulation of important anti-bloating agents, proanthocyanidins (Jones and Lyttleton 1971). Therefore, biochemical and molecular studies on the proanthocyanidin pathway have been performed using $L$. corniculatus and Lotus japonicus (Regel) K.Larsen (Bavage et al. 1997; Escaray et al. 2017; Gruber et al. 2008; Lees 1986; Morris and Robbins 1992; Morris et al. 1993; Robbins et al. 1998; Sivakumaran et al. 2006; Skadhauge et al. 1997), the latter of which has been used as a model legume for molecular genetics and genomics studies (Handberg and Stougaard 1992; Jiang and Gresshoff 1997; Sato et al. 2001, 2008).

Although some flavonoid biosynthetic genes are regulated by developmental cues, the biosynthesis of anthocyanins and other flavonoids is also modulated by environmental conditions (Hrazdina 1982; McClure 1975), such as light (Chappell and Hahlbrock 1984; McNellis and Deng 1995), low temperature (Christie et al. 1994), nutrient availability (Coronado et al. 1995), wounding and pathogen attack (Dixon and Paiva 1995). Sensing the external stimuli and transducing these signals are critical for plant survival; however, the molecular bases of these processes remain to be elucidated. Investigation of the regulation of the flavonoid biosynthesis will advance our understanding of the plant response to environmental stimuli.

In this study, we investigated the effect of environmental conditions on anthocyanin accumulation in the stem of L. japonicus plants by performing mutant screening and genetic analysis. First, we investigated the characteristics of anthocyanin accumulation in L. japonicus B-129 'Gifu' to establish the criteria for screening and evaluating mutants. Next, we isolated and characterized artificial mutants and wild accessions deficient in anthocyanin accumulation, MG-13 'Arasaki', MG-17 'Mishima' and MG-20 'Miyakojima'. Genetic analysis using the mutants and wild accessions identified at least five loci essential for the proper accumulation of anthocyanins in the L. japonicus stems. Since the biosynthetic pathway of anthocyanins is linked to that of flavones, flavonols and proanthocyanidins (Fig. 1), the anthocyanin mutants included mutants with low proanthocyanidin accumulation. Various flavonoid-accumulating
Fig. 1 Flavonoid biosynthetic pathway in leguminous plants. Names of flavonoid skeletons and individual compounds are shown in bold and italics, respectively. ANR anthocyanidin reductase, $A N S$ anthocyanidin synthase, $C H S$ chalcone synthase, $C H I$ chalcone isomerase, $D F R$ dihydroflavonol 4-reductase, $F 3 H$ flavanone $3 \beta$-hydroxylase, FNS flavone synthase, FLS flavonol synthase, $L A R$ leucoanthocyanidin reductase, $L D O X$ leucoanthocyanidin dioxygenase, $P K R$ polyketide reductase

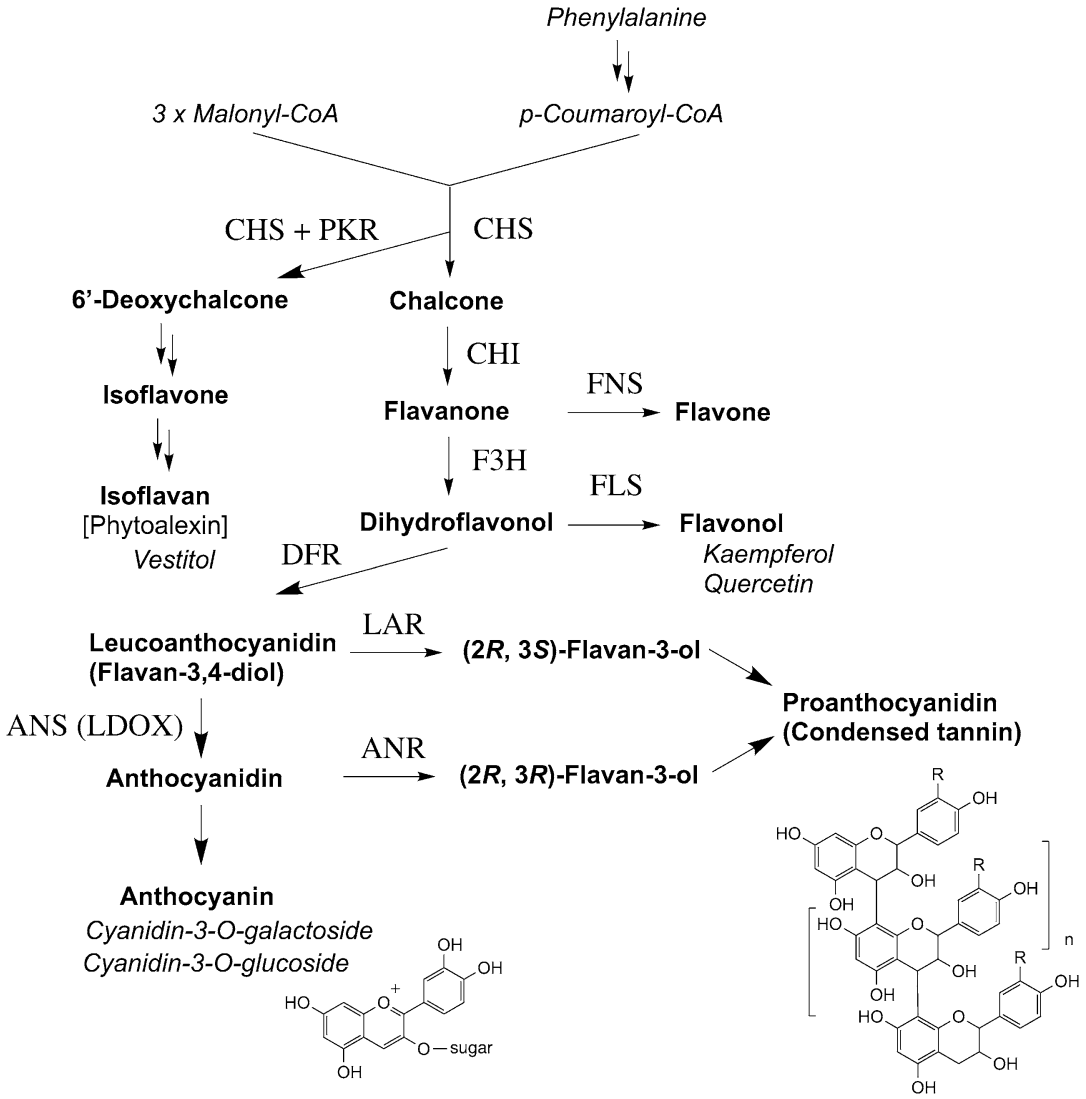


mutants identified in this study and wild accessions should serve as useful resources for elucidating the specific biological roles of flavonoids in legumes.

\section{Materials and methods}

\section{Plant materials and screening for anthocyanin-deficient mutants}

Seeds of L. japonicus accession B-129 'Gifu' (Grant et al. 1962; Handberg and Stougaard 1992) and MG-58 Nichinan were provided by Dr. J. Stougaard (Aarhus University, Denmark) and Dr. T. Shimada (Obihiro University of Agriculture and Veterinary Medicine, Japan), respectively. Other accessions were collected from several areas in Japan (Table 1). The growth conditions in the greenhouse and the ethyl methanesulfonate (EMS) mutagenesis protocol have been previously described (Imaizumi-Anraku et al. 1997). A total of $14,000 \mathrm{M}_{2}$ seeds were sown in low-nutrient artificial soil, and seedlings were grown for 4-8 weeks. In the first screening, plants with no red pigmentation in the stem were selected and transferred to nutrient-rich soil. The putative mutants were then evaluated based on the stem at the flowering stage. Mutant lines were confirmed to be anthocyanindeficient in the $\mathrm{M}_{3}$ generation and crossed with B-129 (wild type). $F_{2}$ plants were grown in low-nutrient artificial soil for 6-8 weeks in a greenhouse, and the segregation of wildtype and anthocyanin-deficient phenotypes was observed. The mutants were grouped into classes and subclasses according to the phenotype. To perform complementation analysis, mutants within the same phenotypic subclass were crossed. To analyse anthocyanin accumulation in young plants in vitro, sterilized seeds were sown in a plastic pot $(7 \mathrm{~cm} \times 7 \mathrm{~cm} \times 10 \mathrm{~cm}$ ) containing B\&D (Broughton and Dilworth 1971) agar (0.9\%) medium supplemented with $\mathrm{KNO}_{3}$ (final concentration, 0.1 or $10 \mathrm{mM}$ ). The pots were sealed with Micropore Surgical Tape (3 M Health Care, St. Paul, MN, USA) to facilitate ventilation. Plants were grown in an incubator (Biotron LH 200, Nippon Medical and Chemical Instruments, Osaka, Japan) at $25^{\circ} \mathrm{C}$ under a 16 -h light/8-h dark cycle.

\section{Root nodule formation}

Mesorhizobium loti strain Tono was isolated from a root nodule of $L$. japonicus accession MG-10 Tono. The isolated bacteria were used to inoculate L. japonicus B-129 seedlings grown on nitrogen-free $B \& D$ agar medium for 2 weeks, as previously described (Imaizumi-Anraku et al. 1997). The formation of root nodules was observed 1 month after inoculation.

\section{Anthocyanin quantification}

Anthocyanins were extracted using $1 \% \mathrm{HCl}$ in methanol and quantified by colorimetry according to the following equation:

Anthocyanin $=A_{530}-\left(0.25 \times A_{657}\right)$

\section{Flavonoid analysis}

Stem segments [ca. $200 \mathrm{mg}$ fresh weight (FW)] were extracted with five volumes of $80 \%$ (v/v) ethanol at $4{ }^{\circ} \mathrm{C}$ overnight. The soluble fraction was hydrolysed with $3 \mathrm{M}$ $\mathrm{HCl}$ at $100{ }^{\circ} \mathrm{C}$ for $2 \mathrm{~h}$ and analysed by high-performance liquid chromatography (HPLC) equipped with a Shim-pack CLC-ODS column (150 mm length, $6 \mathrm{~mm}$ i.d; Shimadzu, Kyoto, Japan) using acetonitrile in water acidified with phosphoric acid $(\mathrm{pH} 3)$ as the mobile phase at a flow rate of $1 \mathrm{~mL} \mathrm{m^{-1 }}$ at $40{ }^{\circ} \mathrm{C}$. Anthocyanidins were analysed with $16 \%$ acetonitrile (monitored at $550 \mathrm{~nm}$ ), and non-anthocyanin flavonoid aglycones were separated with a linear gradient of $20-35 \%$ acetonitrile over 25 min (monitored at $236 \mathrm{~nm})$. The insoluble fraction was treated with $5 \%(\mathrm{w} / \mathrm{v})$ $\mathrm{HCl}$ in $n$-butanol at $90{ }^{\circ} \mathrm{C}$ for $60 \mathrm{~min}$ (Morris and Robbins 1992), yielding anthocyanidins derived from polymerized proanthocyanidins (condensed tannins). Anthocyanin glycosides were extracted with 3\% acetic acid in ethanol at $4{ }^{\circ} \mathrm{C}$ overnight. The extract was partitioned with hexane to remove chlorophylls, and the acetic acid-ethanol layer was analyzed by HPLC using an XBridge C18 column $\left(4.6 \times 150 \mathrm{~mm}\right.$; Waters) at $40{ }^{\circ} \mathrm{C}$ a flow rate of $1.0 \mathrm{~mL} \mathrm{~min}{ }^{-1}$
Table 1 Accessions of $L$. japonicus used in this study

\begin{tabular}{|c|c|c|}
\hline Accession no. & Trivial name & Collection site \\
\hline B-129 & Gifu & See Grant et al. (1962) \\
\hline MG-13 & Arasaki & Yokosuka, Kanagawa. $35^{\circ} 11^{\prime} \mathrm{N}, 139^{\circ} 36^{\prime} \mathrm{E}$ \\
\hline MG-15 & Bishamon & Miura, Kanagawa. $35^{\circ} 8^{\prime} \mathrm{N}, 139^{\circ} 39^{\prime} \mathrm{E}$ \\
\hline MG-17 & Mishima & Mishima, Shizuoka. $35^{\circ} 6^{\prime} \mathrm{N}, 138^{\circ} 56^{\prime} \mathrm{E}$ \\
\hline MG-20 & Miyakojima & $\begin{array}{l}\text { Gusukube (Miyakojima Island), Okinawa. } 24^{\circ} \\
43^{\prime} \mathrm{N}, 125^{\circ} 27^{\prime} \mathrm{E} \text { (Kawaguchi et al. 2001) }\end{array}$ \\
\hline MG-58 & Nichinan & Nichinan, Miyazaki. $31^{\circ} 34^{\prime} \mathrm{N}, 131^{\circ} 24^{\prime} \mathrm{E}$ \\
\hline
\end{tabular}


and a linear gradient elution for $20 \mathrm{~min}$ from 5 to $35 \%$ acetonitrile containing $0.5 \%$ trifluoroacetic acid. Quercetin, kaempferol, cyanidin, cyanidin-3-O-galactoside (idaein) and cyanidin-3-O-glucoside were identified by co-chromatography with authentic samples (Extrasynthese, Genay, France).

\section{Results}

Lotus japonicus accession B-129 'Gifu' accumulates red pigment in the petal, pedicel and stem (Fig. 2a, c, e). We detected two major and several minor anthocyanins in the acidified ethanol extract of stem segments by HPLC (Fig. 3a). Analysis of hydrolysed anthocyanins revealed that cyanidin was the major aglycone. Co-chromatography using authentic samples revealed that cyanidin-3-O-galactoside (idaein) and cyanidin-3-O-glucoside were the abundant anthocyanins in B-129 'Gifu'.

To establish the criteria for the evaluation of mutants, we investigated anthocyanin accumulation in the stem of the standard accession B-129 'Gifu'. Stem cross-sections of B-129 plants cultivated in a greenhouse were obtained and further divided longitudinally into five. Anthocyanin concentrations were determined in these longitudinal sections. Figure 4 shows representative results using a standard cultivation condition. Anthocyanin first accumulated in two basal parts (I and II) at 2-7 weeks postgermination. At the flowering stage ( 9 weeks post-germination), anthocyanin accumulation was prominent in all four basal parts (I-IV), with the highest concentration in part I. At 16 weeks post-germination, the entire stem had accumulated a large amount of anthocyanin, which was almost the same as that in part I of 9-week-old plants. These results suggest several effective criteria for evaluating phenotypes of anthocyanin accumulation in the stem of L. japonicus. In cases where convenience is a priority, red or purple pigmentation can be a visual marker of anthocyanin accumulation in B-129 plants older than 4 weeks of age. Further unequivocal determination of the phenotype requires other criteria based on the developmental stage, instead of the period after germination, since plant growth and development are influenced by cultivation conditions, such as nutrition, temperature and light. Results shown in Fig. 4 and other independent observations suggest that the anthocyanin concentration in part I of the stem and the extent of pigmentation at the flowering stage would serve as excellent markers of anthocyanin accumulation (Fig. 2e). Red pigmentation, which appeared as red streaks on the standard petal and pedicel (Fig. 2a, c), serve as additional criteria.

The accelerated accumulation of red pigments in the stem of mutants deficient in symbiotic nitrogen fixation (Schauser et al. 1999) implied the significance of nitrogen in the regulation of stem anthocyanin biosynthesis. To determine the effect of nitrogen on anthocyanin biosynthesis, B-129 plants were grown on B\&D agar medium supplemented with permissive $(10 \mathrm{mM})$ or limiting $(0.1 \mathrm{mM})$ concentrations of $\mathrm{KNO}_{3}$ for 4 weeks. Anthocyanin accumulation was markedly enhanced under the nitrogen-limiting condition, particularly under high light intensity $(260 \mu \mathrm{mol}$ photons $\mathrm{m}^{-2} \mathrm{~s}^{-1}$ ) (Fig. 5). These results suggest that cultivation under nitrogen-deficient conditions enhances red pigmentation in
Fig. 2 Anthocyanin accumulation and proanthocyanidin detection in Lotus japonicus B-129 'Gifu' and vic mutants. a and $\mathbf{b}$ Petals of B-129 (a) and vic3 (b). c and d Pedicels (arrowheads) of B-129 (c) and vic3 (d). e B-129 (centre) and vicl-1 (right) at the flowering stage. Left, 3-week old B-129 plant. f Pod and seeds of B-129 (left) and vicl-2 (right). g Detection of polymerized proanthocyanidins (condensed tannins). The insoluble fraction of the stem was treated with $5 \%$ $\mathrm{HCl}$ in $n$-butanol at $90{ }^{\circ} \mathrm{C}$ for $60 \mathrm{~min}$. Proanthocyanidins were converted to relevant anthocyanidins with red colour. Left to right: B-129, vic1-1, vic2, vic3, vic1-2 and vic4-1

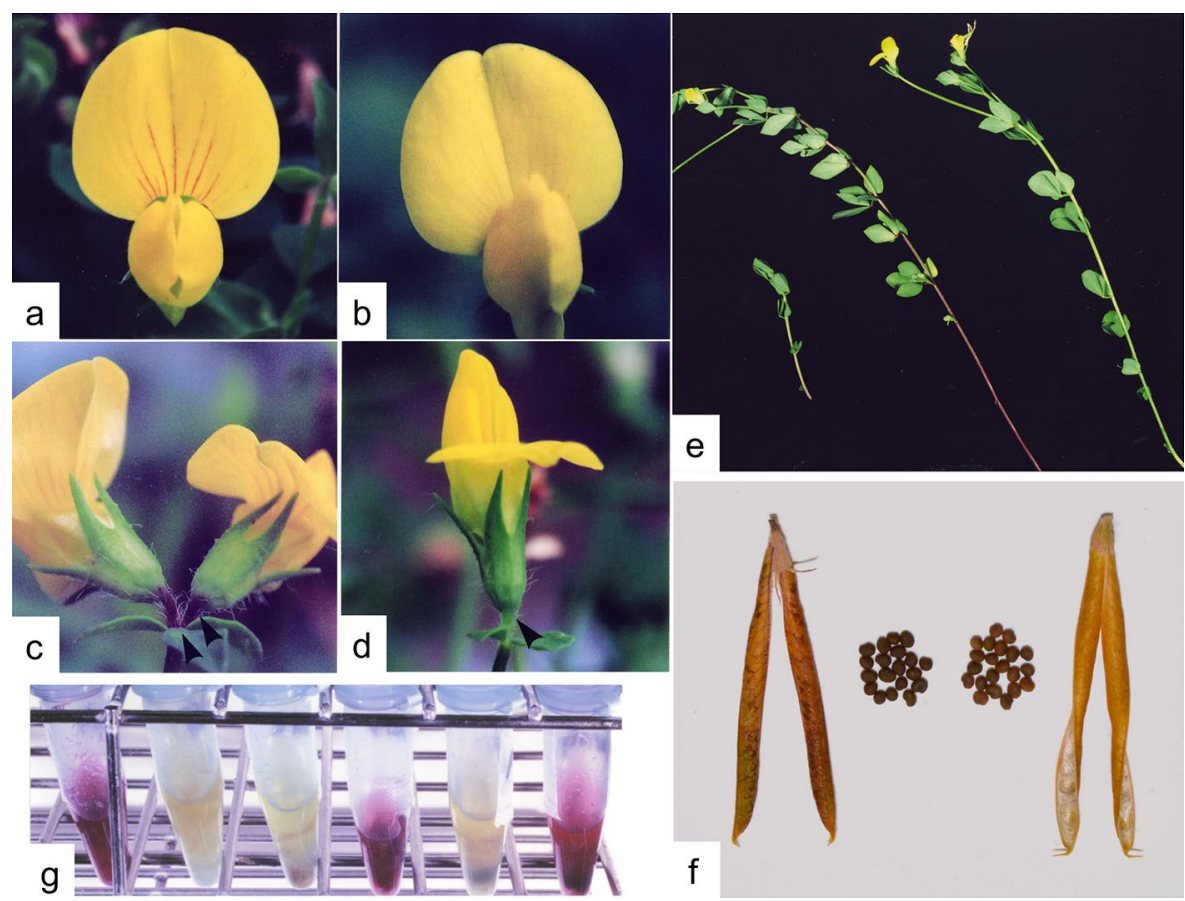




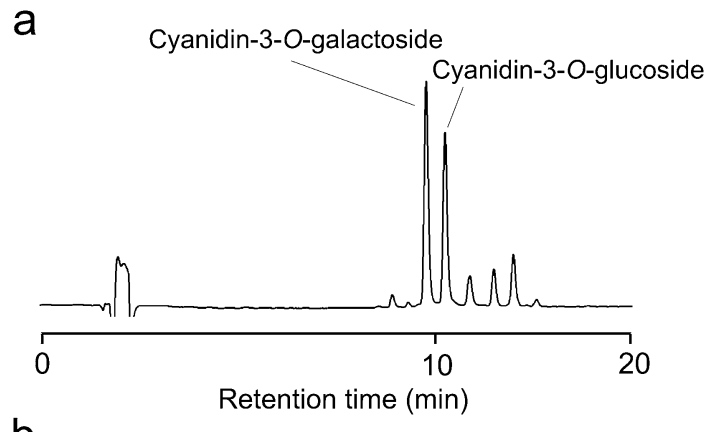

b
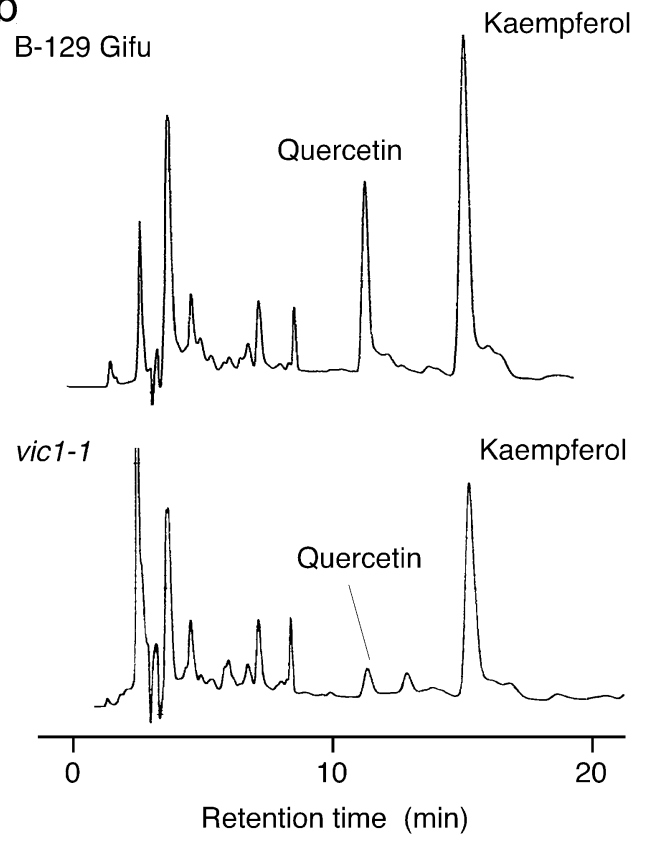

Fig. 3 HPLC profiles of stem extracts of L. japonicus. a Anthocyanins extracted from B-129. HPLC was monitored at $520 \mathrm{~nm}$. b Flavonoid aglycones isolated from B-129 and vicl-1 (a class 1 mutant). Stem extracts with $80 \%$ (v/v) ethanol were hydrolysed with $3 \mathrm{M} \mathrm{HCl}$ at $100{ }^{\circ} \mathrm{C}$ for $2 \mathrm{~h}$ and analysed by HPLC at $236 \mathrm{~nm}$ wild-type stems, thus making the difference between wild and mutant phenotypes more apparent.

The $\mathrm{M}_{2}$ progenies of EMS-treated seeds were screened for anthocyanin-deficient mutants at two stages: first at 4-8 weeks post-germination and then at the flowering stage. Ten putative mutant lines were selected. After the confirmation of mutant traits and normal development in the $\mathrm{M}_{3}$ generation, five mutant lines with strikingly low anthocyanin concentration were selected. A similar approach was used to screen wild accessions collected from several areas in Japan, and three accessions (MG-13, MG-17 and MG-20) with low anthocyanin accumulation were selected (Table 1).

Loci involved in the stem anthocyanin accumulation were named VIRIDICAULIS (VIC) for the green (viridi-) stem (caulis). Table 2 summarizes the vic mutants identified so far. Genetic analysis by backcrossing with B-129 'Gifu' revealed that five EMS-induced mutants and two wild accessions (MG-13 and MG-20) showed monogenic recessive inheritance (Table 2). On the other hand, anthocyanin accumulation in one wild accession, MG-17, was suggested to be regulated by two loci, based on the 15:1 segregation ratio observed in the $\mathrm{F}_{2}$ generation (Table 2). Mutants and natural variants were divided into two classes, according to the degree of anthocyanin deficiency. Phenotypes in class 1 were characterized by complete anthocyanin deficiency in the stem and standard petal (Ant ${ }^{-}$; Fig. 2b, e). On the other hand, phenotypes in class 2 accumulated anthocyanins to some extent, but the concentrations in the stem are distinctly low $\left(\mathrm{Ant}^{ \pm}\right)$compared with the wild type B-129. Complementation tests of class 1 genotypes revealed four loci (vic1-vic4). Furthermore, complementation tests across class 1 and 2 genotypes revealed that MG-20 is a new allele of vic4 and the $\mathrm{Ant}^{ \pm}$ mutant (which was isolated from EMS-mutagenized lines) represents a new locus (data not shown). Based on these results, MG-20 and the $\mathrm{Ant}^{ \pm}$mutant were named as vic4-2 and vic5, respectively. Anthocyanin deficiency in the stem
Fig. 4 Stem anthocyanin content of L. japonicus plants grown in soil. Stems were cut into five parts and extracted with $1 \% \mathrm{HCl}$ in methanol. Anthocyanin content was determined by colorimetry. The arrow shows the border of the visible pigmented area. The horizontal bar represents the standard error (SE; $n=3$ ). Data of B-129 'Gifu' and vic5 (a class 2 mutant with lowered anthocyanin accumulation) are shown

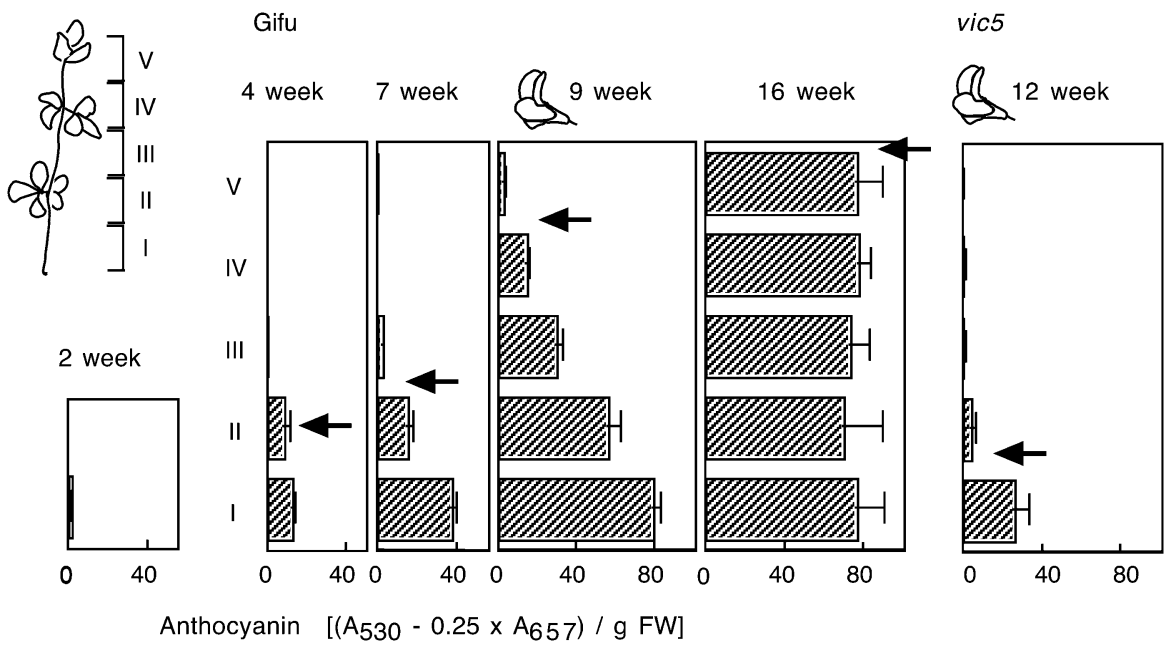




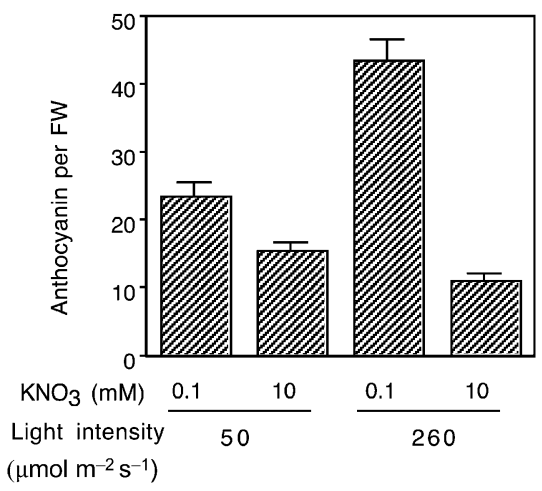

Fig. 5 Anthocyanin content in L. japonicus B-129 seedlings. Sterilized seeds were sown on B\&D agar media containing indicated concentrations of $\mathrm{KNO}_{3}$ and cultivated for 4 weeks. The vertical bar shows the $\mathrm{SE}(n=8)$

Table 2 List of anthocyanin-deficient mutants of $L$. japonicus

\begin{tabular}{|c|c|c|c|c|c|}
\hline Locus & Origin $^{a}$ & Phenotype $^{b}$ & $\begin{array}{l}\text { Backcross } \\
\text { segregation }^{c} \\
\text { N: M }\end{array}$ & Expected ratio & $\chi^{2 \mathrm{~d}}$ \\
\hline \multicolumn{6}{|c|}{ Class 1 (completely anthocyanin deficient) } \\
\hline vic1-1 & EMS & $\mathrm{Ant}^{-} \mathrm{Tan}^{-}$ & 140: 49 & 3: 1 & 0.086 \\
\hline vic1-2 & EMS & Ant $^{-} \operatorname{Tan}^{-}$ & 143: 43 & 3: 1 & 0.351 \\
\hline$v i c 2$ & EMS & $\mathrm{Ant}^{-} \mathrm{Tan}^{-}$ & 69: 21 & 3: 1 & 0.133 \\
\hline vic3 & MG-13 & $\mathrm{Ant}^{-} \mathrm{Tan}^{+}$ & 133: 46 & 3: 1 & 0.046 \\
\hline vic4-1 & EMS & $\mathrm{Ant}^{-} \mathrm{Tan}^{+}$ & 185: 62 & 3: 1 & 0.001 \\
\hline \multicolumn{6}{|c|}{ Class 2 (lowered anthocyanin) } \\
\hline$v i c 5$ & EMS & $\mathrm{Ant}^{ \pm} \operatorname{Tan}^{+}$ & $122: 34$ & $3: 1$ & 0.854 \\
\hline vic4-2 & MG-20 & $\mathrm{Ant}^{ \pm} \operatorname{Tan}^{+}$ & 111: 39 & $3: 1$ & 0.080 \\
\hline$v i c^{\mathrm{e}}$ & MG-17 & $\mathrm{Ant}^{ \pm} \operatorname{Tan}^{+}$ & 208: 18 & 15: 1 & 1.133 \\
\hline
\end{tabular}

${ }^{a} E M S$ mutagenesis by EMS treatment of seeds. See Table 1 for the accessions

${ }^{\mathrm{b}}$ Ant anthocyanin accumulation, Tan condensed tannin (polymerized proanthocyanidins) accumulation. The standard wild type B-129 'Gifu' is $\mathrm{Ant}^{+} \mathrm{Tan}^{+}$

${ }^{\mathrm{c}} N$ normal phenotype, $M$ mutant phenotype, number of each phenotype observed in the $\mathrm{F}_{2}$ generation is shown

${ }^{\mathrm{d}} \mathrm{A}$ value of less than 3.8 indicates that the segregation is not significantly different from the expected ratio $(p>0.05)$

${ }^{\mathrm{e}}$ Unidentified loci

of a representative class 2 mutant, vic5, at the flowering stage is shown in Fig. 4. The difference between B-129 and vic 5 was evident based on the above-described criteria, i.e. anthocyanin concentration in part I and the distribution of anthocyanin (Fig. 4). Two Ant ${ }^{ \pm}$class 2 lines, vic4-2 and vic5, showed slightly red streaks on the standard petal, while the other Ant ${ }^{ \pm}$class 2 lines (MG-15 'Bishamon', MG-17 'Mishima' and MG-58 'Nichinan') showed clear streaks, similar to the petal of B-129 'Gifu' (Table 3). Red pigmentation in the pedicel was absent in all class

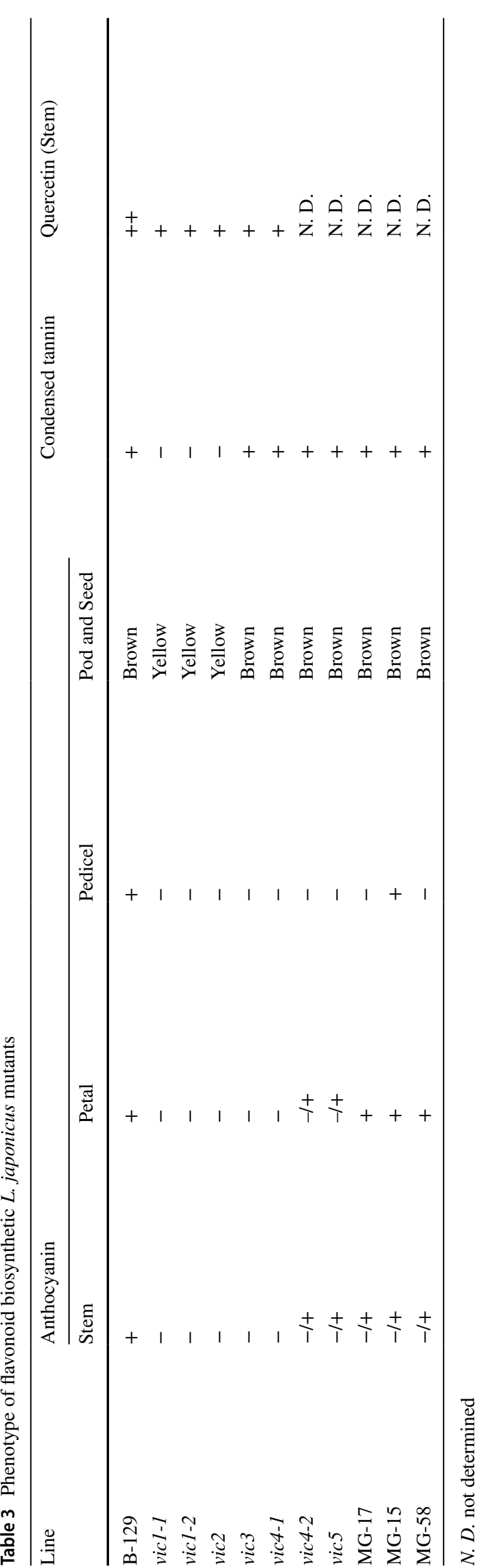


1 genotypes (Fig. 2d) and in Ant ${ }^{ \pm}$class 2 mutant and wild accessions, except MG-15 (Table 3). Severe nutrient limitation and long-term cultivation slightly accelerated the stem pigmentation in $\mathrm{Ant}^{ \pm}$lines but had no effect on anthocyanin accumulation in $\mathrm{Ant}^{-}$lines (data not shown).

Anthocyanins are biosynthesized via the phenylpropanoid/flavonoid pathway. The composition of related flavonoids can be used to characterize anthocyanin biosynthesis mutants. HPLC analysis after hydrolysis of aqueous ethanol extract revealed that two flavonols, kaempferol and quercetin, were the major soluble non-anthocyanin flavonoid aglycones in the stem of B-129 'Gifu'. A class 1 mutant, vicl-1, also contained both flavonols although the level of quercetin was relatively low (Fig. 3b). Flavonol concentrations in other class 1 mutants were highly similar (data not shown). These results suggest that in all class 1 mutants obtained, the mutant genes did not significantly affect the flavonoid pathway prior to the biosynthesis of dihydroflavonols (Fig. 1).

Proanthocyanidins are another class related to anthocyanins in the metabolic pathway (Fig. 1). In this study, polymerized proanthocyanidins (condensed tannins) were analysed by conversion to red anthocyanidins by heating with $\mathrm{HCl}$ in $n$-butanol. Figure $2 \mathrm{~g}$ shows the presence of proanthocyanidins in the stem of B-129 and two class 1 mutants (vic3 and vic4-1) and its absence in vicl-1, vicl-2 and vic2. The three procyanidin-deficient mutants set yellow seeds and pods (Fig. 2f), whereas vic 3 and vic4 presented a wild-type phenotype (brown pods and seeds) (Table 3). Strong genetic linkage of the three traits, no anthocyanin, no proanthocyanidin, and yellow seeds in the $\mathrm{Ant}^{-} \mathrm{Tan}^{-}$mutants (Table 1) was suggested by the observation that more than ten $\mathrm{F}_{2}$ plants of no anthocyanin also lacked proanthocyanidins and set yellow pods and that no recombinant phenotype (e.g., no anthocyanin and brown seeds) was observed.

Next, nodule formation on the roots of $\mathrm{Ant}^{-} \mathrm{Tan}^{-}$mutants was compared with that on the roots of B-129 plants using a domestic strain of $M$. loti (Tono). However, no significant difference was detected in the number, size and appearance of root nodules between $\mathrm{Ant}^{-} \mathrm{Tan}^{-}$mutants and B-129 (data not shown).

\section{Discussion}

Arabidopsis thaliana is the first model plant of the postgenomic era, and L. japonicus and Medicago truncatula are established as the major model of the Leguminosae family. This study was started in the last century at a very early stage of the research history of $L$. japonicus as a model organism, when information on the flavonoid composition of $L$. japonicus was limited (Morris et al. 1993; Nakaoki et al. 1956). Subsequently, metabolic profiling of $L$. japonicus by liquid chromatography Fourier transform ion cyclotron resonance mass spectrometry (LC-FTICR/MS) revealed ca. 60 flavonoids, mainly comprising flavonol glycosides and anthocyanins including cyanidin 3-O-galactoside and cyanidin-3-O-glucoside reported in this study (Suzuki et al. 2008). In addition, comparison of B-129 and MG-20 confirmed that B-129 stem contains cyanidin- and peonidinbased anthocyanins, whereas MG-20 stem contains no anthocyanin (Suzuki et al. 2008). Also, the tandem mass spectral database was helpful in connecting the metabolic quantitative trait loci (QTLs) of L. japonicus with individual flavonoid components (Sawada et al. 2012).

During the past 2 decades, progress in the research on the biosynthesis of isoflavonoids, which are characteristically dominant in the Leguminosae, has been documented using L. japonicus and other bioresources of this family. Elicitation of $L$. japonicus seedlings by reduced glutathione demonstrated the occurrence of vestitol, an isoflavan phytoalexin (Shimada et al. 2000). The enzymes of the vestitol biosynthesis pathway have been completely clarified, and the corresponding genes have been identified (Akashi et al. 2003, 2005, 2006; Shimamura et al. 2007; Uchida et al. 2017). Identification of the multigene families of the flavonoid/isoflavonoid biosynthetic enzymes in $L$. japonicus and their expression analysis upon elicitation and/or rhizobial infection have yielded important clues on the evolution of specific biosynthetic pathways and active and selective responses to biological and environmental stimuli (Akashi et al. 2006; Shimada et al. 2003, 2005, 2007).

Besides isoflavonoids, three related flavonoid classes of legumes, namely, anthocyanins, proanthocyanidins and flavonols, have gained significant attention for their role in plant-environment interactions (see below) and their exact biosynthetic pathway and mechanisms of metabolic control. For example, flavonoids have been shown to be important for nodule organogenesis; flavonols and isoflavones/flavones function as auxin transport inhibitors and rhizobial nod gene inducers, respectively (Subramanian et al. 2006; Wasson et al. 2006; Zhang et al. 2009). Despite the advances in our understanding of the biosynthetic relationship of anthocyanins and proanthocyanidins, the mechanism regulating the biosynthesis of oligo- and polymeric proanthocyanidins remains elusive. In L. japonicus, while the red stem colour and red streaks on the standard petal have been noted (de Nettangourt and Grant 1964; Grant et al. 1962; Schauser et al. 1999), these have not been sufficiently investigated either chemically or physiologically.

In this study, the criteria for screening and evaluating $L$. japonicus mutants defective in stem anthocyanin accumulation were developed based on the spatiotemporal characteristics of anthocyanin accumulation. These characteristics were identified using plants grown in a greenhouse for up to 12 weeks or using seedlings grown on agar media 
in vitro. The characteristics identified were as follows: (1) anthocyanin accumulation in the stem increased with the developmental stage or cultivation period, (2) extended from the lower part to the upper parts and (3) was enhanced by nitrogen limitation and intense illumination (Figs. 2 and 4). It has been reported that nitrogen availability can alter flavonoid biosynthesis in several plant species (McClure 1975), particularly in vegetative organs such as the root and stem (Bongue-Bartelsman and Phillips 1995; Cho and Harper 1991a, b; Coronado et al. 1995; Lea et al. 2007). Lightdependent anthocyanin production is a typical photoresponse, which is controlled by signals from photoreceptors (Fankhauser and Chory 1997). Anthocyanin accumulation in vegetative organs can be used as a visual marker for the genetic and physiological analysis of the signalling of environmental stimuli.

Artificially induced mutants and wild accessions of $L$. japonicus were categorized into three groups $\left(\mathrm{Ant}^{-} \mathrm{Tan}^{-}\right.$, $\mathrm{Ant}^{-} \mathrm{Tan}^{+}$and $\left.\mathrm{Ant}^{ \pm}\right)$, according to flavonoid deficiency (Table 2). A barley (Hordeum vulgare) anthocyanin mutant, ant-13, deficient in proanthocyanidins showed extreme susceptibility to powdery mildew (von Wettstein et al. 1977), which suggests that proanthocyanidins are involved in plant defence. Lotus mutants lacking proanthocyanidins (vicl and vic2) should serve as a useful system for testing the participation of proanthocyanidins in the interaction of the host with herbivorous pests, pathogenic microorganisms and nitrogen-fixing symbionts. In this study, nodule formation in $\mathrm{Tan}^{-}$mutants showed no difference from that in the wild type (B-129) upon inoculation with a domestic strain of $M$. loti (Tono). However, in right of the reported case that even the same L. japonicus mutant shows a different nodulation phenotype depending on the inoculated rhizobial strains (Shimoda et al. 2020; Yamaya-Ito et al. 2018), the effect of vic mutations on nodulation should be tested further using various $M$. loti strains and non-symbiotic rhizobia of L. japonicus. On the other hand, the interaction with rhizosphere microbiota via root exudates has attracted a great deal of attention in recent years. The effect of vic mutants on the rhizosphere microbiota would also be an interesting issue (Okutani et al. 2020; Sugiyama and Yazaki 2014; Suseela et al. 2016; Zhalnina et al. 2018).

Genetic analysis of $\mathrm{Ant}^{-} \mathrm{Tan}^{-}$mutants of $L$. japonicus (vicl and vic2) indicated that at least two loci are essential for anthocyanin and proanthocyanidin biosynthesis. The presence of quercetin (Fig. 3b) in these mutants suggests that the biosynthetic pathway is functional up to the production of dihydroflavonol (Fig. 1). The simplest hypothesis is that the biosynthesis in the $\mathrm{Ant}^{-} \mathrm{Tan}^{-}$mutants is blocked at the step producing leucoanthocyanidins (flavan-3,4-diols) from dihydroflavonols, which is catalysed by dihydroflavonol 4-reductase (DFR). The other class 1 mutants, vic3 and vic4, contained polymerized proanthocyanidins (Fig. 2g). Genetic blocking of biosynthesis is likely to occur at the synthesis of cyanidin by leucoanthocyanidin dioxygenase (LDOX) (Saito et al. 1999), also known as anthocyanidin synthase (ANS). The other possibility is that VIC genes control several structural genes for anthocyanin/proanthocyanidin biosynthesis.

Well-investigated Arabidopsis loci essential for flavonoid biosynthesis are those collectively named as TRANSPARENT TESTA (TT) and TRANSPARENT TESTA GLABROUS (TTG), based on the reduced or abolished pigmentation in the seed coat of $t t$ and $t t g$ mutants (Appelhagen et al. 2014; Saito et al. 2013; Winkel-Shirley et al. 1995). Seed coat pigments are thought to be related to the proanthocyanidin pathway (Abrahams et al. 2002). Some TT genes encode biosynthetic enzymes (Chang et al. 1988; Feinbaum and Ausbel 1988; Winkel-Shirley et al. 1992) and regulatory factors (Nesi et al. 2000; Walker et al. 1999). The seed colour of L. japonicus $\mathrm{Ant}^{-} \mathrm{Tan}^{-}$mutants was similar to that of Arabidopsis $t t$ mutants, but only limited variation of $\mathrm{Ant}^{-} \mathrm{Tan}^{-}$mutants has been identified so far. Further screening would facilitate the identification of mutants defective in other steps of anthocyanin biosynthesis because the scale of screening in this study $\left(14,000 \mathrm{M}_{2}\right.$ seeds) was far smaller than that expected to saturate the loci essential for anthocyanin accumulation. However, we could not exclude the possibility that structural and regulatory genes involved in some steps of the pathway exhibit redundant functions in L. japonicus (Fig. 1) or that mutants defective in the early steps are sterile or lethal. It is noteworthy that the TT2 homologs of $L$. japonicus contribute to proanthocyanidin accumulation mediated by anthocyanidin reductase (ANR) (see below; Yoshida et al. 2008). Moreover, LjTT2 (R2R2MYB protein), LjTT8 (bHLH protein) and LjTTG1 (WDR protein) form a ternary transcription complex that acts on the promoter of $L j D F R 2$, one of the five paralogous $D F R$ genes of $L$. japonicus (Shimada et al. 2005), leading to proanthocyanidin biosynthesis, while the substitution of LjTT2 in the ternary complex with LjPAP leads to the biosynthesis of anthocyanins (Yoshida et al. 2010).

Stereoisomers of flavan-3-ols are intermediates for the biosynthesis of proanthocyanidin oligomers and produced through at least two pathways characterized by representative enzymes (Fig. 1). The activity of leucoanthocyanidin reductase (LAR) was detected in Lotus cell free extract (Skadhauge et al. 1997). The ANR enzyme was shown to be encoded by the BANYULS gene in Arabidopsis and its orthologs in M. truncatula (Devic et al. 1999; Xie et al. 2003) and Lotus spp. (Paolocci et al. 2007; Yoshida et al. 2008). In Arabidopsis seeds, the ANR pathway is probably a dominant pathway for proanthocyanidin biosynthesis because the $t$ t 18 mutant, which lacks LDOX activity, had greatly reduced levels of proanthocyanidins (Xie et al. 2003). The phenotype of Ant ${ }^{-} \mathrm{Tan}^{+}$mutants of Lotus spp., such as vic3 and vic4, suggests that the LAR pathway, which 
is independent of anthocyanidin biosynthesis, may function as a bypass for the production of proanthocyanidins in Lotus stems. However, considering a new pathway into a flavan-3-ol stereoisomer reported for M. truncatula (Jun et al. 2018), detailed examination of the proanthocyanidin stereochemistry and the biosynthetic enzymes involved, possibly taking advantage of these vic mutants, may lead to important findings, which could help understand this complicated metabolic pathway.

In a previous study, 17 characteristics of 66 L. japonicus accessions collected from different regions of Japan were evaluated, and the correlation among traits and between traits and geographic conditions of the habitats were statistically analysed (Suginobu et al. 1988). Stem colour (anthocyanin content), leaf colour (chlorophyll content) and plant weight showed a significant correlation among each other and with the latitude. The correlation between the anthocyanin content and other physiological characteristics implies that genes partially involved in flavonoid biosynthesis are pleiotropic and perform physiological roles in environmental adaptation and/or growth and development.

The wild accessions of $L$. japonicus described in this study showed considerable variation in anthocyanin accumulation and inheritance of the mutant phenotype (Table 2). It is noteworthy that the collection sites of MG-13, MG-15 and MG-17 accessions were no more than $60 \mathrm{~km}$ away from each other. In some cases, wild accessions coexisted with other plants exhibiting the wild-type stem colour at the collection sites. These facts suggest marked diversity of anthocyanin accumulation in wild-grown $L$. japonicus, although the underlying reason is unknown. It is also unclear whether the variants are fully adapted to the environment of their habitat since the number of individuals with the mutant phenotype varied among the collection sites. Several plants of the MG-15, MG-20 and MG-58 accessions were clustered at the collection sites; however, only single plants of MG-13 and MG-17 were found at a given site. Thus, the frequency of $L$. japonicus individuals with a green stem also varied.

Numerous plants have been used in molecular and genetic studies of the flavonoid pathway. Several L. japonicus resources are now available for molecular genetics and genomics analyses (Asamizu et al. 2000a, b; Fukai et al. 2012; Hashiguchi et al. 2018; Hayashi et al. 2001; Kamal et al. 2020; Li et al. 2020; Nakamura et al. 2002; Pedrosa et al. 2002; Sandal et al. 2002; Sato et al. 2001, 2008). Fine mapping for cloning the VIC genes is currently under progress. L. japonicus is a model plant and represents another system especially suitable for exploring the regulation of anthocyanin biosynthesis in vegetative organs and the specific functions of flavonoids in leguminous plants.

Acknowledgements The authors are grateful to Drs. Jens Stougaard and Toru Shimada for the provision of $L$. japonicus B-129 and MG-58, respectively, and Miwa Aoki for collecting accessions MG-15 and MG-17. A chemical mutagen EMS was kindly provided by Ohsumi laboratory. The authors also thank Emiko Kobayashi, Takako Minato, Dr. Nobuyuki Terouchi and Shinobu Niwa for technical assistance. This work was supported by Grant-in-Aid for Scientific Research on Priority Areas (A) and the High-tech Research Center Project of the Ministry of Education, Culture, Sports, Science and Technology, Japan. Professor Toshio Aoki (1961-2019), the first author and the principal investigator of this work, passed away after about 2 years of illness. The study reported here is a small part of his lifework started during his early career and continued throughout his profession at Nihon University from 1996. Professor Aoki designed and conducted the central parts of this research, including collection of naturally growing $L$. japonicus, mutant screening, genetic analysis, and flavonoid analysis. Professor Shoichiro Akao (1943-2012) has also played an essential role in the early phases of this study, supporting cultivation and genetic analysis of L. japonicus for many years. The present publication has been approved by the bereaved families of the late Professors T. Aoki and S. Akao as respective representatives, and is dedicated to their memories.

Open Access This article is licensed under a Creative Commons Attribution 4.0 International License, which permits use, sharing, adaptation, distribution and reproduction in any medium or format, as long as you give appropriate credit to the original author(s) and the source, provide a link to the Creative Commons licence, and indicate if changes were made. The images or other third party material in this article are included in the article's Creative Commons licence, unless indicated otherwise in a credit line to the material. If material is not included in the article's Creative Commons licence and your intended use is not permitted by statutory regulation or exceeds the permitted use, you will need to obtain permission directly from the copyright holder. To view a copy of this licence, visit http://creativecommons.org/licenses/by/4.0/.

\section{References}

Abrahams S, Tanner GJ, Larkin PJ, Ashton AR (2002) Identification and biochemical characterization of mutants in the proanthocyanidin pathway in Arabidopsis. Plant Physiol 130:561-576

Akashi T, Sawada Y, Shimada N, Sakurai N, Aoki T, Ayabe S (2003) cDNA cloning and biochemical characterization of $S$-adenosylL-methionine: 2,7,4'-trihydroxyisoflavanone 4'-O-methyltransferase, a critical enzyme of the legume isoflavonoid phytoalexin pathway. Plant Cell Physiol 44:103-112

Akashi T, Aoki T, Ayabe S (2005) Molecular and biochemical characterization of 2-hydroxyisoflavanone dehydratase. Involvement of carboxylesterase-like proteins in leguminous isoflavone biosynthesis. Plant Physiol 137:882-891

Akashi T, Koshimizu S, Aoki T, Ayabe S (2006) Identification of cDNAs encoding pterocarpan reductase involved in isoflavan phytoalexin biosynthesis in Lotus japonicus by EST mining. FEBS Lett 580:5666-5670

Aoki T, Akashi T, Ayabe S (2000) Flavonoid of leguminous plants: structure, biological activity, and biosynthesis. J Plant Res 113:475-488

Appelhagen I, Thiedig K, Nordholt N, Schmidt N, Huep G, Sagasser M, Weisshaar B (2014) Update on transparent testa mutants from Arabidopsis thaliana: characterisation of new alleles from an isogenic collection. Planta 240:955-970

Asamizu E, Nakamura Y, Sato S, Tabata S (2000a) Generation of 7137 non-redundant expressed sequence tags from a legume, Lotus japonicus. DNA Res 7:127-130 
Asamizu E, Watanabe M, Tabata S (2000b) Large scale structural analysis of cDNAs in the model legume, Lotus japonicus. J Plant Res 113:451-455

Bavage AD, Davies IG, Robbins MP, Morris P (1997) Expression of an antirrhinum dihydroflavonol reductase gene results in changes in condensed tannin structure and accumulation in root cultures of Lotus corniculatus (bird's foot trefoil). Plant Mol Biol 35:443-458

Bongue-Bartelsman M, Phillips DA (1995) Nitrogen stress regulates gene expression of enzymes in the flavonoid biosynthetic pathway of tomato. Plant Physiol Biochem 33:539-546

Broughton WJ, Dilworth MY (1971) Control of leghemoglobin synthesis in snake beans. Biochem J 125:1075-1080

Buer CS, Djordjevic MA (2009) Architectural phenotypes in the transparent testa mutants of Arabidopsis thaliana. J Exp Bot 60:751-763

Chan BG, Waiss AC, Lukefahr M (1978) Condensed tannin and antibiotic chemical from Gossypium hirsutum. J Insect Physiol 24:113-118

Chang C, Bowman JL, DeJohn AW, Lander ES, Meyerowitz EM (1988) Restriction fragment length polymorphism linkage map for Arabidopsis thaliana. Proc Natl Acad Sci USA 85:6856-6860

Chappell J, Hahlbrock K (1984) The transcription of plant defense genes in response to UV light or fungal elicitor. Nature 311:76-78

Charrier B, Trinh H, Poirier S, Kondorosi A, Ratat P (1998) Flavanone 3-hydroxylase $(\mathrm{F} 3 \mathrm{H})$ expression and flavonoid localization in nodules of three legume plants reveal distinct tissue specificities. Mol Plant Microbe Interact 9:924-932

Cho M-J, Harper JE (1991a) Effect of inoculation and nitrogen on isoflavonoid concentration in wild-type and nodulation-mutant soybean roots. Plant Physiol 95:435-442

Cho M-J, Harper JE (1991b) Effect of localized nitrate application on isoflavonoid concentration and nodulation in split-root system of wild-type and nodulation mutant soybean plants. Plant Physiol 95:1106-1112

Christie PJ, Alfenito MR, Walbot V (1994) Impact of low-temperature stress on general phenylpropanoid and anthocyanin pathways: enhancement of transcript abundance and anthocyanin pigmentation in maize seedlings. Planta 194:541-549

Coronado C, Zuanazzi JAS, Sallaud C, Quirion JC, Esnalt R, Husson HP, Kondorosi A, Ratet P (1995) Alfalfa root flavonoid production is nitrogen regulated. Plant Physiol 108:533-542

de Nettangourt D, Grant WF (1964) Gene inheritance and linkage relationships in interspecific diploid hybrids closely related to Lotus corniculatus L. Can J Genet Cytol 6:277-287

Devic M, Guilleminot J, Debeaujon I, Bechtold N, Bensaude E, Koornneef M, Pelletier G, Delseny M (1999) The BANYULS gene encodes a DFR-like protein and is a marker of early seed coat development. Plant J 19:387-398

Dixon RA, Paiva NL (1995) Stress-induced phenylpropanoid metabolism. Plant Cell 7:1085-1097

Dixon RA, Steele CL (1999) Flavonoids and isoflavonoids-a gold mine for metabolic engineering. Trends Plant Sci 4:394-400

Escaray FJ, Passeri V, Perea-Garcia A, Antonelli CJ, Damiani F, Ruiz OA, Paolocci F (2017) The R2R3-MYB TT2 $b$ and the bHLH TT8 genes are the major regulators of proanthocyanidin biosynthesis in the leaves of Lotus species. Planta 246:243-261

Fankhauser C, Chory J (1997) Light control of plant development. Annu Rev Cell Dev Biol 13:203-229

Feinbaum RL, Ausbel FM (1988) Transcriptional regulation of the Arabidopsis thaliana chalcone synthase gene. Mol Cell Biol 8:1985-1992

Forkmann G (1994) Genetics of flavonoids. In: Harborne JB (ed) The flavonoids. Advances in research since 1986. Chapman and Hall, London, pp 537-564
Franssen HJ, Vijn I, Yang WC, Bisseling T (1992) Developmental aspects of the rhizobium-legume symbiosis. Plant Mol Biol 19:89-107

Fukai E, Soyano T, Umehara Y, Nakayama S, Hirakawa H, Tabata S, Sato S, Hayashi M (2012) Establishment of a Lotus japonicus gene tagging population using the exon-targeting endogenous retrotransposon LORE1. Plant J 69:720-730

Grant WF, Bullen MR, de Nettancourt D (1962) The cytogenetics of Lotus. I. Embryo-cultured interspecific diploid hybrids closely related to Lotus corniculatus L. Can J Genet Cytol 4:105-128

Gruber M, Skadhauge B, Yu M, Muir A, Richards K (2008) Variation in morphology, plant habit, proanthocyanidins, and flavonoids within a Lotus germplasm collection. Can J Plant Sci $88: 121-132$

Handberg K, Stougaard J (1992) Lotus japonicus, an autogamous, diploid legume species for classical and molecular genetics. Plant J 2:487-496

Hashiguchi M, Tanaka H, Muguerza M, Akashi R, Sandal NN, Andersen SU, Sato S (2018) Lotus japonicus genetic, mutant, and germplasm resources. Curr Protoc Plant Biol 3:e20070. https ://doi.org/10.1002/cppb.20070

Haslam E (1998) Practical polyphenolics: from structure to molecular recognition and physiological action. Cambridge University Press, Cambridge

Hassan S, Mathesius U (2012) The role of flavonoids in root-rhizosphere signalling: opportunities and challenges for improving plant-microbe interactions. J Exp Bot 63:3429-3444

Hayashi M, Miyahara A, Sato S, Kato T, Yoshikawa M, Taketa M, Hayashi M, Pedrosa A, Onda R, Imaizumi-Anraku H, Bachmair A, Sandal N, Stougaard J, Murooka Y, Tabata S, Kawasaki S, Kawaguchi M, Harada K (2001) Construction of a genetic linkage map of the model legume Lotus japonicus using an intraspecific $\mathrm{F}_{2}$ population. DNA Res 8:301-310

Holton TA, Cornish EC (1995) Genetics and biochemistry of anthocyanin biosynthesis. Plant Cell 7:1071-1083

Hrazdina G (1982) Anthocyanins. In: Harborne JB, Mabry TJ (eds) The flavonoids. Advances in research. Chapman and Hall, London, pp 135-188

Imaizumi-Anraku H, Kawaguchi M, Koiwa H, Akao S, Syono K (1997) Two ineffective-nodulating mutants of Lotus japonicas - different phenotypes caused by the blockage of endocytotic bacterial release and nodule maturation. Plant Cell Physiol 38:871-881

Jacobs M, Rubery PH (1988) Naturally occurring auxin transport regulators. Science 241:346-349

Jiang Q, Gresshoff PM (1997) Classical and molecular genetics of the model legume Lotus japonicus. Mol Plant Microbe Interact 10:59-68

Jones WT, Lyttleton JW (1971) Bloat in cattle. XXXIV. A survey of forages that do and do not produce bloat. $\mathrm{N} Z \mathrm{~J}$ Agric Res 13:101-107

Jones WT, MacDonald PE, Jones SD, Pankhurst CE (1987) Peptidoglycan-bound polysaccharide associated with resistance of Rhizobium loti strain NZP2037 to Lotus pedunculatus root flavolan. J Gen Microbiol 133:2617-2629

Jun JH, Xiao X, Rao X, Dixon RA (2018) Proanthocyanidin subunit composition determined by functionally diverged dioxygenases. Nat Plants 4:1034-1043

Kamal N, Mun T, Reid D, Lin JS, Akyol TY, Sandal N, Asp T, Hirakawa H, Stougaard J, Mayer KFX, Sato S, Andersen SU (2020) Insights into the evolution of symbiosis gene copy number and distribution from a chromosome-scale Lotus japonicus Gifu genome sequence. DNA Res. https://doi.org/10.1093/dnare s/dsaa015

Kawaguchi M, Motomura T, Imaizumi-Anraku H, Akao S, Kawasaki S (2001) Providing the basis for genomics in Lotus japonicus: 
the accessions Miyakojima and Gifu are appropriate crossing partners for genetic analyses. Mol Genet Genomics 266:157-166

Lea US, Slimestad R, Smedvig P, Lillo C (2007) Nitrogen deficiency enhances expression of specific MYB and bHLH transcription factors and accumulation of end products in the flavonoid pathway. Planta 225:1245-1253

Lees GL (1986) Condensed tannins in the tissue culture of sainfoin (Onobrychis viciifolia Scop.) and birdsfoot trefoil (Lotus corniculatus L.). Plant Cell Rep 5:247-251

Li J, Ou-Lee T, Raba R, Amundson RG, Last RL (1993) Arabidopsis flavonoid mutants are hypersensitive to UV-B irradiation. Plant Cell 5:171-179

Li H, Jiang F, Wu P, Wang K, Cao Y (2020) A high-quality genome sequence of model legume Lotus japonicus (MG-20) provides insights into the evolution of root nodule symbiosis. Genes (Basel) 11:483

Long SR (1996) Rhizobium symbiosis: Nod factors in perspective. Plant Cell 8:1885-1898

Mathesius U (2001) Flavonoids induced in cells undergoing nodule organogenesis in white clover are regulators of auxin breakdown by peroxidase. J Exp Bot 52:419-426

Mathesius U, Schlaman HRM, Spaink HP, Sautter C, Rolfe BG, Djordjevic MA (1998) Auxin transport inhibition precedes root nodule formation in white clover roots and is regulated by flavonoids and derivatives of chitin oligosaccharides. Plant J 14:23-34

McClure JW (1975) Physiology and functions of flavonoids. In: Harborne JB, Mabry TJ, Mabry H (eds) The flavonoids. Chapman and Hall, London, pp 970-1055

McNellis TW, Deng XW (1995) Light control of seedling morphogenetic pattern. Plant Cell 7:1749-1761

Morimoto S, Tateishi N, Matsuda T, Tanaka H, Taura F, Furuya N, Matsuyama N, Shoyama Y (1998) Novel hydrogen peroxide metabolism in suspension cells of Scutellaria baicalensis Georgi. J Biol Chem 273:12606-12611

Morris P, Robbins MP (1992) Condensed tannin formation by Agrobacterium rhizogenes transformed root and shoot organ cultures of Lotus corniculatus. J Exp Bot 43:221-231

Morris P, Carron TR, Robbins MP, Webb KJ (1993) Distribution of condensed tannins in flowering plants of Lotus corniculatus var japonicus and tannin accumulation by transformed root cultures. Lotus Newsl 24:60-64

Mulder-Krieger TH, Verpoorte P (1994) Anthocyanins as flower pigments: feasibilities for flower colour modification. Kluwer Academic Publishers, Dordrecht

Nakamura Y, Kaneko T, Asamizu E, Kato T, Sato S, Tabata S (2002) Structural analysis of a Lotus japonicus genome. II. Sequence features and mapping of sixty-five TAC clones which cover the 6.5-Mb regions of the genome. DNA Res 9:63-70

Nakaoki T, Morita N, Hiraki A, Kurokawa Y (1956) Studies on medicinal resources. V. Components of the leaves of Lotus corniculatus L. var. japonicus Regel., Mikrolespedeza striata Makino, Magnolia obovata Thunb., and Abutilon avicennae Gaertn. Yakugaku Zasshi 76:347-349 (In Japanese)

Nesi N, Debeaujon I, Jond C, Pelletier C, Caboche M, Lepiniec L (2000) The $T T$ gene encodes a basic helix-loop-helix domain protein required for expression of $D F R$ and $B A N$ genes in Arabidopsis siliques. Plant Cell 12:1863-1878

Okutani F, Hamamoto S, Aoki Y, Nakayasu M, Nihei N, Nishimura T, Yazaki K, Sugiyama A (2020) Rhizosphere modeling reveals spatiotemporal distribution of daidzein shaping soybean rhizosphere bacterial community. Plant Cell Environ 43:1036-1046

Paolocci F, Robbins MP, Madeo L, Arcioni S, Martens S, Damiani F (2007) Ectopic expression of a basic helix-loop-helix gene transactivates parallel pathways of proanthocyanidin biosynthesis. Structure, expression analysis, and genetic control of leucoanthocyanidin 4-reductase and anthocyanidin reductase genes in Lotus corniculatus. Plant Physiol 143:504-516

Park KI, Nitasaka E, Hoshino A (2018) Anthocyanin mutants of Japanese and common morning glories exhibit normal proanthocyanidin accumulation in seed coats. Plant Biotechnol 35:259-266

Pedrosa A, Sandal N, Stougaard J, Schweizer D, Bachmair A (2002) Chromosomal map of the model legume Lotus japonicus. Genetics 161:1661-1672

Peer WA, Murphy AS (2007) Flavonoids and auxin transport: modulators or regulators? Trends Plant Sci 12:556-563

Punkhurst CE, Jones WT (1979) Effectiveness of Lotus root nodules: 2. Relationship between root nodule effectiveness and 'in vitro' sensitivity of fast-growing Lotus rhizobia to flavolans. J Exp Bot 30:1095-1107

Robbins MP, Bavage AD, Strudwicke C, Morris P (1998) Genetic manipulation of condensed tannins in higher plants: II Analysis of birdsfoot trefoil plants harboring antisense dihydroflavonol reductase constructs. Plant Physiol 116:1133-1144

Saito K, Kobayashi M, Gong Z, Tanaka Y, Yamazaki M (1999) Direct evidence for anthocyanidin synthase as a 2-oxoglutarate-dependent oxygenase: molecular cloning and functional expression of cDNA from a red forma of Perilla frutescens. Plant J 17:181-189

Saito K, Yonekura-Sakakibara K, Nakabayashi R, Higashi Y, Yamazaki M, Tohge T, Fernie AR (2013) The flavonoid biosynthetic pathway in Arabidopsis: structural and genetic diversity. Plant Physiol Biochem 72:21-34

Sandal N, Krusell L, Radutoiu S, Olbryt M, Pedrosa A, Stracke S, Sato S, Kato T, Tabata S, Parniske M, Bachmair A, Ketelsen T, Stougaard J (2002) A genetic linkage map of the model legume Lotus japonicus and strategies for fast mapping of new loci. Genetics 161:1673-1683

Sato S, Kaneko T, Nakamura Y, Asamizu E, Kato T, Tabata S (2001) Structural analysis of a Lotus japonicus genome. I. Sequence features and mapping of fifty-six TAC clones which cover the $5.4 \mathrm{Mb}$ regions of the genome. DNA Res 8:311-318

Sato S, Nakamura Y, Kaneko T, Asamizu E, Kato T, Nakao M, Sasamoto S, Watanabe A, Ono A, Kawashima K, Fujishiro T, Katoh M, Kohara M, Kishida Y, Minami C, Nakayama S, Nakazaki N, Shimizu Y, Shinpo S, Takahashi C, Wada T, Yamada M, Ohmido N, Hayashi M, Fukui K, Baba T, Nakamichi T, Mori H, Tabata S (2008) Genome structure of the legume, Lotus japonicus. DNA Res 15:227-239

Sawada Y, Nakabayashi R, Yamada Y, Suzuki M, Sato M, Sakata A, Akiyama K, Sakurai T, Matsuda F, Aoki T, Hirai MY, Saito K (2012) RIKEN tandem mass spectral database (ReSpect) for phytochemicals: a plant-specific MS/MS-based data resource and database. Phytochemistry 82:38-45

Schauser L, Roussis A, Stiller J, Stougaard J (1999) A plant regulator controlling development of symbiotic root nodules. Nature 402:191-195

Sharma M, Cortes-Cruz M, Ahern KR, McMullen M, Brutnell T, Chopra S (2011) Identification of the Prl gene product completes the anthocyanin biosynthesis pathway of maize. Genetics 188:69-79

Shimada N, Akashi T, Ayabe AT, S, (2000) Induction of isoflavonoid pathway in the model legume Lotus japonicus: molecular characterization of enzymes involved in phytoalexin biosynthesis. Plant Sci 160:37-47

Shimada N, Aoki T, Sato S, Nakamura Y, Tabata S, Ayabe S (2003) A cluster of genes encodes the two types of chalcone isomerase involved in the biosynthesis of general flavonoids and legume-specific 5-deoxy(iso)flavonoids in Lotus japonicus. Plant Physiol 131:941-951

Shimada N, Sasaki R, Sato S, Kaneko T, Tabata S, Aoki T, Ayabe S (2005) A comprehensive analysis of six dihydroflavonol 
4-reductases encoded by a gene cluster of the Lotus japonicus genome. J Exp Bot 56:2573-2585

Shimada N, Sato S, Akashi T, Nakamura Y, Tabata S, Ayabe S, Aoki T (2007) Genome-wide analyses of the structural gene families involved in the legume-specific 5-deoxyisoflavonoid biosynthesis of Lotus japonicus. DNA Res 14:25-36

Shimamura M, Akashi T, Sakurai N, Suzuki H, Saito K, Shibata D, Ayabe S, Aoki T (2007) 2-Hydroxyisoflavanone dehydratase is a critical determinant of isoflavone productivity in hairy root cultures of Lotus japonicus. Plant Cell Physiol 48:1652-1657

Shimoda Y, Nishigaya Y, Yamaya-Ito H, Inagaki N, Umehara Y, Hirakawa H, Sato S, Yamazaki T, Hayashi M (2020) The rhizobial autotransporter determines the symbiotic nitrogen fixation activity of Lotus japonicus in a host-specific manner. Proc Natl Acad Sci USA 117:1806-1815

Sivakumaran S, Rumball W, Lane GA, Fraser K, Foo LY, Yu M, Meagher LP (2006) Variation of proanthocyanidins in Lotus species. J Chem Ecol 32:1797-1816

Skadhauge B, Gruber MY, Thomsen KK, von Wettstein D (1997) Leucocyanidin reductase activity and accumulation of proanthocyanidins in developing legume tissues. Am J Bot 84:494-503

Spaink H (1998) Flavonoids as regulators of plant development. In: Romeo JT, Downum KR, Verpoorte R (eds) Phytochemical and plant-microbe interactions. Plenum Press, New York, pp 167-177

Stapleton AE, Walbot V (1994) Flavonoids can protect maize DNA from the induction of ultraviolet radiation damage. Plant Physiol 105:881-889

Subramanian S, Stacey G, Yu O (2006) Endogenous isoflavones are essential for the establishment of symbiosis between soybean and Bradyrhizobium japonicum. Plant J 48:261-273

Suginobu K, Suzuki S, Komatsu T (1988) Evaluation of the characteristics in miyakogusa (Lotus corniculatus L. var. japonicus Regel) 3. Characteristics of local strains collected from different regions in Japan. J Jpn Soc Grassl Sci 34:1-6 (In Japanese)

Sugiyama A, Yazaki K (2014) Flavonoids in plant rhizospheres: secretion, fate and their effects on biological communication. Plant Biotechnol 31:431-443

Suseela V, Alpert P, Nakatsu CH, Armstrong A, Tharayil N (2016) Plant-soil interactions regulate the identity of soil carbon in invaded ecosystems: implication for legacy effects. Funct Ecol 30:1227-1238

Suzuki H, Sasaki R, Ogata Y, Nakamura Y, Sakurai N, Kitajima M, Takayama H, Kanaya S, Aoki K, Shibata D, Saito K (2008) Metabolic profiling of flavonoids in Lotus japonicus using liquid chromatography Fourier transform ion cyclotron resonance mass spectrometry. Phytochemistry 69:99-111

Uchida K, Akash T, Aoki T (2017) The missing link in leguminous pterocarpan biosynthesis is a dirigent domain-containing protein with isoflavanol dehydratase activity. Plant Cell Physiol 58:398-408

van der Meer IM, Stam ME, van Tunen AJ, Mol JNM, Stuitje AR (1992) Antisense inhibition of flavonoid biosynthesis in petunia anthers results in male sterility. Plant Cell 4:253-262

von Wettstein D, Jende-Strid B, Ahrenst-Larsen B, Sorensen JA (1977) Biochemical mutant in barley renders chemical stabilization of beer superfluous. Carlsberg Res Commun 42:341-351
Walker AR, Davison PA, Bolognesi-Winfield AC, James CM, Srinivasan N, Blundell TL, Esch JJ, Marks MD, Gray JC (1999) The TRANSPARENT TESTA GLABRA1 locus, which regulates trichome differentiation and anthocyanin biosynthesis in Arabidopsis, encodes a WD40 repeat protein. Plant Cell 11:1337-1350

Wasson AP, Pellerone FI, Mathesius U (2006) Silencing the flavonoid pathway in Medicago truncatula inhibits root nodule formation and prevents auxin transport regulation by rhizobia. Plant Cell 18:1617-1629

Winkel-Shirley B (2001) Flavonoid biosynthesis. A colorful model for genetics, biochemistry, cell biology, and biotechnology. Plant Physiol 126:485-493

Winkel-Shirley B, Hanley S, Goodman HM (1992) Effects of ionizing radiation on a plant genome: analysis of two Arabidopsis transparent testa mutation. Plant Cell 4:333-347

Winkel-Shirley B, Kubasek WL, Storz G, Bruggemann E, Koornneef M, Ausubel FM, Goodman HM (1995) Analysis of Arabidopsis mutants deficient in flavonoid biosynthesis. Plant J 8:659-671

Xie D, Sharma SB, Paiva NL, Ferreira D, Dixon RA (2003) Role of anthocyanidin reductase, encoded by BANYULS in plant flavonoid biosynthesis. Sceince 299:396-399

Yamasaki H, Sakihama Y, Ikehara N (1997) Flavonoid-peroxidase reaction as a detoxification mechanism of plant cells against $\mathrm{H}_{2} \mathrm{O}_{2}$. Plant Physiol 115:1405-1412

Yamaya-Ito H, Shimoda Y, Hakoyama T, Sato S, Kaneko T, Hossain MS, Shibata S, Kawaguchi M, Hayashi M, Kouchi H, Umehara Y (2018) Loss-of-function of ASPARTIC PEPTIDASE NODULEINDUCED 1 (APN1) in Lotus japonicus restricts efficient nitrogen-fixing symbiosis with specific Mesorhizobium loti strains. Plant J 93:5-16

Ylstra B, Busscher J, Franken J, Hollman PCH, Mol JNM, van Tunen AJ (1994) Flavonols and fertilization in Petunia hybrida: Localization and mode of action during pollen tube growth. Plant $\mathrm{J}$ 6:201-212

Yoshida K, Iwasaka R, Kaneko T, Sato S, Tabata S, Sakuta M (2008) Functional differentiation of Lotus japonicus TT2s, R2R3-MYB transcription factors comprising a multigene family. Plant Cell Physiol 49:157-169

Yoshida K, Iwasaka R, Shimada N, Ayabe S, Aoki T, Sakuta M (2010) Transcriptional control of the dihydroflavonol 4-reductase multigene family in Lotus japonicus. J Plant Res 123:801-805

Zhalnina K, Louie KB, Hao Z, Mansoori N, da Rocha UN, Shi S, Cho H, Karaoz U, Loqué D, Bowen BP, Firestone MK, Northen TR, Brodie EL (2018) Dynamic root exudate chemistry and microbial substrate preferences drive patterns in rhizosphere microbial community assembly. Nat Microbiol 3:470-480

Zhang J, Subramanian S, Stacey G, Yu O (2009) Flavones and flavonols play distinct critical roles during nodulation of Medicago truncatula by Sinorhizobium meliloti. Plant J 57:171-183

Publisher's Note Springer Nature remains neutral with regard to jurisdictional claims in published maps and institutional affiliations. 